\title{
Genetic Redundancy Eliminates the Dream of Beneficial Mutations
}

\author{
Haitham Talaat* \\ Civil Engineering, Egypt
}

Submission: November 04, 2017; Published: December 21, 2017

*Corresponding author: Haitham Talaat, Civil Engineering, Samalout, Minia, Egypt, Email: haithamsrour41@gmail.com

\section{Abstract}

Redundancy is the duplication of a system's components or functions in order to increase its reliability. Whereas the system is provided with redundant models of the main components to make alternate copies available to face any sudden failure. A satellite is comprised of redundant primary components before it is sent to space. An example of this is the inertial navigation system, which relies on five redundant computers on board, and there are three identical inertia measurement units.

The same concept exists in living beings, whereas gene redundancy makes living beings safe from any sudden gene mutation of knockout. Hence, redundancy is a biological safety system which removes the effect of mutations Redundant mechanisms' duty is to achieve the aims of growth in complete perfection. This mechanism is necessary; as there is no system with such complexity as that of living organisms unless it will need the redundancy in its different phases of Decoding.

This Phenomenon imposes a giant challenge to the conception of beneficial mutations. In order to get a beneficial mutation with evident effect, this mutation should have the same semblance and technique in all the redundant copies which produce this effect in a genome. The more redundant the genes are, the more we need synchronizing effective mutations on the progressive change, and the more difficult it is to believe in the ability of this change to get a wholesome model.

This article sheds light on the decisive difficulties which face the hope of inducing any beneficial mutations.

\section{Redundancy's Function in Genes}

In space shuttles and high-tech equipment, there exist redundant copies for sensitive navigation systems, which lead to quickly bypassing any emergency and avoiding any problem due to the existence of intact substitutes to which no harm was done due to emergency Tomayko JE [1].

For instance,

A. Skylab: (a space station launched by NASA) was managed by two giant Computers, both of which had the same tasks because they were congruous copies, so that if one failed the other took the same tasks.

B. Saturn rocket model: Used triple modular redundant (TMR) as model of computer used 3 congruous copies of directing programs.

C. Spacelab: The Shuttle used five identical redundant IBM 32-bit general purpose computers (GPCs), model AP-101, constituting a type of embedded system [2] and many other examples, but this is a different context.
D. Parallel computing: Improves the efficiency of high-technology systems to the extent of perfect performance. Synchronization of efficiency in redundant circuits is the suitable way to ensure the reliability of electronic devices.

It's been demonstrated through the transfer of engineering to biological devices which exist at the organisms since the 1990s, that there are completely redundant components which protect the organisms from the random mutations, whereas these biotic components exist in the genome in many copies as a strategy to fulfil the developmental target and the protection of the organism. If any of these copies fail, the others perform the same function with the same efficiency. Decoding takes place within the other copy to produce the same proteins produced by that copy, avoiding any failures that may have damaged the previous copies Able KP [3].

It's amazing that these information are encoded in two different ways, this staggering feature manufactures the same results in ways other than the congruous copies. If the original gene loses its function, the redundant gene takes over and keeps the cell alive. 


\section{Examples of original genes which lost their functions while the cell was still alive}

A. The gene that encode Tenascin- $\mathrm{C}$ was lost from mice while the protein was still alive with the same productive efficiency Erickson HP [4].

B. Zeste (so biotic gene Encodes proteins that transmit zones of DNA) was lost from the Drosophila, after the transmission it remained without changes in its function Goldberg ML [5].

This phenomenon is not a partial one in living systems; rather, it is the basis, and genes redundancy is one of the principles of DNA's strand, whereas you could see no gene without being redundant elsewhere Sternberg PW [6].

Homologous sequences are paralogous if created by a duplication event within the genome. For gene duplication events, if a gene of an organism is duplicated to occupy two different positions in the same genome, then the two copies are paralogous. Paralogous sequences provide useful and dramatic functions Studer RA and Nehrt NL $[7,8]$.

\section{Redundancy eliminates the dream of beneficial mutations}

If you change one of the redirecting programs into the Spacecraft, Irrespective of your thinking is it right or not, the other copies will recorrect any damages which may happen because there are always other congruous copies can receive easily the original data with perfect reliability. So, if you decided to modulate the data for better performance in one of the redirecting programs, you should carry out this change discreetly in every copy at the same time and place. Any other attempt will cause damage in the program in general if your changes take place in different areas of the identical copies, or else your changes will be useless if they were not applied on every copy.

Therefore, Trying to manufacture synthetic mutations in the Drosophila leads to induce only a strange flaw in its shape or function because mutations weren't in the same postures in the same characters Gauchat D [9].

The most important condition of what was mention is that a mutation must produce a benefit. And that a mutation must occur at the same time, at the same place.

Thus, if you want to arrange the conditions for producing a beneficial mutation, you would require the following:

a. An alteration in the form or the arrangement of letters

b. An alteration of letters that produces a beneficial mutation

c. The alteration must occur in the exact place

d. The alteration must occur at the same time

If one of these conditions was not met, the alteration shall have no place, nor shall it have meaning.
Hence, redundancy destroys the dream of beneficial mutations.

\section{Redundancy is a duplication in every developmental level}

Redundancy is a system that exists in every growth level. Redundancy is not confined to single (individual) genes or to a certain level of growth for the living being; rather, it is a phenomenon that exists in all levels, and what is fascinating as was mentioned earlier in this article is that redundancy does not produce with the existence of identical gene copies only, but also produces via other alternatives, as it produces a function through identical copies as well as alternatives which produce the same function, whereas the growth function, whatever its type, a target for the cell for which it directs all its units to achieve, and this occurs by direct means though identical genes, or indirect ones which we know nothing much about Wilson SW [10].

In an independent study of the reproductive system for the filarial nematode Brugia malayi, in which the traditional hybridization method was used, it was indeed observed that the reproductive system arises via different genetic methods and many available alternatives that exist on the DNA strap Daojun Jiang [11].

And this poses a stranger and more complicated issue, as this is not just identical redundancy for producing a functional system; rather, this functional system began producing alternatives other than identical copies, and in order to have a beneficial mutation in this context, you are in need to know the secrets of available alternatives in order to produce that system which you will be adjusting (altering). And after knowing all available alternatives, you must apply the four conditions mentioned above requirements.

\section{What is the implication of identical and non-identical redundancy in living beings?}

This is not a philosophical question, and although it has many philosophical implications, it remains a geometrical (engineering) question in the first place. Achieving growth goal requires a practical error rate that is close to zero, such a high level of identical and non-identical redundancy for all functional systems in a living being is not something additional, but rather something essential and necessary; as we do not have a system which contains such a degree of complexity that is similar to the complexity of living beings.

This strange and fascinating phenomenon poses a fundamental challenge to the idea of the possibility of the evolution of a living being as a consequence of consecutive small mutation. If we were to assume that a beneficial mutation occurred in one of the genes of a living being, then all of the give conditions mentioned about must be met, in addition to conducting parallel changes in all copies, the identical and nonidentical ones, and the more complex redundancy becomes, the 
more the ability to conduct geometrical tasks becomes hard to believe.

If we were to assume that we have a catalogue for making an electric light bulb, and this catalogue contains the basic components for making the electric light: the filament, a lead wire to conduct electricity to the filament, inert gas which protects the filament and does not react with it or with electricity, glass which prevents air from entering and inert gas from escaping or else the filament would burn out, and the bulb base which connects the bulb with the socket to make a path for the electric current.

This catalogue contains more than one copy in its pages, whereas if one copy is ruined, there would be another copy in which the same method of manufacturing exists. If we assume the appearance of additional information in one of the copies that could transform this electric light to an amplified laser light, the benefit of this magical additional information will not appear because there are other copies that will ruin and stop its function, hence, there must be parallel changes in all copies in order to make the laser light.

\section{The sixth condition (additional)}

It is important to note that beneficial mutations need a sixth additional condition which was not mentioned, which is: finetuning the remaining organs of the living being to accept and accommodate for the compensated changes in the organ.

For instance, in order to change the eye of a wild animal such as the bear in case it evolves into a whale the origin of species, we will not just need changes in the system which exists in the whale's eyes to adapt to the new water environment only! Rather, we are in need of fundamental changes in the visual perception center in the brain, the composition of the Cerebellum and the eyelid, the endurance of the Sclera, and the eye's ability to see in a water environment that is full of impurities. We would also be in need of other required adaptations that are necessary for providing visual perception under water. And this puts Darwin's theory before a real problem.

«I can see no difficulty in a race of bears being rendered, by natural selection, more and more aquatic in their structure and habits, with larger and larger mouths, till a creature was produced as monstrous as a whale Darwin CR [12]".

\section{Discussion}

\section{What's the possibility of applying duplication mutation simultaneously in more than one redundant model?}

If you believe in the beneficial mutations whereas it's statistically impossible to take place in all redundancies at the same time and format, then hold still that mutation is the source of all biological systems, it has nothing to do with empirical observational science.

If you put a possibility for mutational growth in one of the
Nucleotide pairs simultaneously in all the redundancies with the symbolization to that Nucleotide pair with $(\mathrm{N})$, the number of redundancies with (R), to apply it simultaneously by counting the generation's age and the possibility of mutation with $(\mathrm{t})$ there is a need to $(\mathrm{N})$ exponent $(\mathrm{S})$ exponent $(\mathrm{T})$ of the chances.

Assuming that the average of encryption by the simplest functional systems is 100 thousands of base-Nitrogen pairs, the lowest number of Redundancies in no time for the generation regardless about the average of mutation, the ratio won't be enough for the whole universe because the universe's age is 10 exponent $17 \mathrm{sec}$. Whereas the very least possibility for mutation simultaneously in all duplications transcend 100.000 exponent 2 exponent $2 \mathrm{sec}$, that equalizes 10 exponent $20 \mathrm{sec}$ that equalizes billions of the universe's age $[2,13]$

\section{Conclusion}

Scientific and statistical mathematical objection over the mutations system destroys every hope and every dream of being able to generate a beneficial functional system, and in case we wanted a new living being to appear, then we would be taking about entertaining stories for children, and not about observational, probabilistic, or empirical science.

\section{References}

1. Tomayko JE (1986) Digital Fly-By-Wire: A Case of Bidirectional Technology Transfer in Aerospace Historian. 33(1): 10-18.

2. Ferguson RC, Tate R, Thompson HC (2016) Implementing space shuttle data processing system concepts in programmable logic devices.

3. Able KP (1980) Mechanism and orientation, Navigation and Homing in Animal Migration, New York Academic Press, USA, p. 59-61.

4. Erickson HP (1993) Tenascin-C Tenascin-R Tenascin-X: A Family of Talented Proteins in Search of Functions, Current Biology, p. 869.

5. Goldberg ML, Colvin RA, Mellin AF (1989) The Drosophila Zeste Locus is nonessential Genetics 123(1): 145-155.

6. Sternberg PW (1993) Intercellular signaling and signal transduction in C. Efegans. Annual Review of Genetics p. 512.

7. Studer RA, Robinson-Rechavi M (2009) How confident can we be that orthologs are similar, but paralogs differ? Trends in Genetics 25(5): 210-216.

8. Nehrt NL, Clark WT, Radivojac P, Hahn MW (2011) Testing the ortholog conjecture with comparative functional genomic data from mammals. PLoS Comput Biol 7(6): e1002073.

9. Gauchat D, Mazet F, Berney C, Schummer M, Kreger S, et al. (2000) Evolution of Antp-Class Genes And Differential Expression Of Hydra Hox/Parahox Genes In Anterior Patterning. Proceedings of The National Academy of Sciences of the United States of America, Vol. 97 No. 9 (Apr. 25, 2000), pp. 4493-4498.

10. Wilson SW (1993) Clues from Clueless. Current Biology, p. 539.

11. Jiang D, Li BW, Fischer PU, Weil GJ (2008) Localization of genderregulated gene expression in the filarial nematode Brugia malayi International Journal for Parasitology 38(5): 503-512.

12. Darwin C (1998) The Origin of the Species, Wordsworth Classics, CH6, p. 184.

13. Pérez-Pérez JM, Candela H, Micol JL (2009) Understanding synergy in genetic interactions. Trends Genet 25(8): 368-376. 
(C) This work is licensed under Creative

BY DOI: 10.19080/AIBM.2017.07.555724

\section{Your next submission with Juniper Publishers will reach you the below assets}

- Quality Editorial service

- Swift Peer Review

- Reprints availability

- E-prints Service

- Manuscript Podcast for convenient understanding

- Global attainment for your research

- Manuscript accessibility in different formats

( Pdf, E-pub, Full Text, Audio)

- Unceasing customer service

Track the below URL for one-step submission https://juniperpublishers.com/online-submission.php 